\title{
Estudantes africanos em universidades brasileiras: os desafios da internacionalização "às avessas" no cotidiano universitário
}

\author{
African students in Brazilian universities: the challenges of internationalization \\ at home in university daily life
}

\author{
Estudiantes africanus en universidades brasileras: los desafios de la \\ internacionalizacion "al reves" en el dia a dia de la Universidad
}

\author{
MARIA ISABEL DA CUNHA* \\ GILDO VOLPATO** \\ MARIA APARECIDA MARQUES ROCHA*** \\ MARIALVA MOOG PINTO****
}

\begin{abstract}
RESUMO
O objetivo da pesquisa foi compreender o processo de internacionalização da educação superior e os impactos dele advindo a partir da presença de estudantes estrangeiros africanos em duas universidades brasileiras. A abordagem foi qualitativa e foi utilizado o questionário e a entrevista semiestruturada. Dentre os motivos de estudar no Brasil destaca-se o maior reconhecimento do diploma estrangeiro e o diferencial na formação profissional e inclusão no mercado. Como desafios ressaltam a adaptação às variações linguísticas e dificuldades com conteúdo que não possuem base. Pretendem retornar à Angola para ajudar a reconstruir o país. Os gestores revelaram conhecer as estratégias institucionais de internacionalização, destacando a sustentabilidade e a divulgação das ações institucionais como forma de dar maior visibilidade e fortalecer a imagem institucional. Apoiam este processo, recebendo e acolhendo os estudantes estrangeiros.
\end{abstract}

Palavras-chave: Internacionalização. Educação Superior. Estudantes africanos.

\begin{abstract}
The objective of this research was to understand the internationalization process in higher education and its impacts, considering the presence of African students in two Brazilian universities. The approach of the research was qualitative and a questionnaire has been applied with students, as well as a semi-structured interview made with the managing board. Among the reasons to study in Brazil, some of them stand out such as: a bigger acknowledgement of a foreign diploma, also a professional formation differential and improvement in the labor force inclusion. As challenges, they highlight the adaptation to linguistic variations and writing, including their difficulty with contents they had not been exposed to. They revealed they intend to return to Angola in order to help with their country's reconstruction, since that nation faced a civil war for 30 years. The managers revealed to be aware of the institutional strategies for internationalization, emphasizing sustainability and institutional actions dissemination as ways to give more visibility and turn the institutional image stronger. They support this process, hosting and sheltering those students and mention the social, cultural and academic values that come up from these experiences.
\end{abstract}

Keywords: Internationalization. Higher Education. African students.

\section{RESUMEN}

El objetivo de la investigación era comprender el proceso de internacionalización de la educación superior y el impacto que surge de la presencia de estudiantes extranjeros africanos en dos universidades brasileras. El enfoque de la investigación fue cualitativa y se administró un cuestionario a los estudiantes y llevó a cabo la entrevista semiestructurada con los gestores. Entre las razones para estudiar en Brasil pone de relieve el creciente reconocimiento

\footnotetext{
* Graduada em Ciências Sociais e em Pedagogia na Universidade Católica de Pelotas. Mestrado em Educação pela Pontifícia Universidade Católica do Rio Grande do Sul (PUCRS). Doutorado em Educação pela Universidade Estadual de Campinas (UNICAMP). E-mail: < cunhami@uol.com.br>.

** Graduado em Educação Física pela ESEDE. Mestre em Educação Física, área de concentração: Teoria e Prática Pedagógica, pela Universidade Federal de Santa Catarina (UFSC) e Doutor em Educação pela Universidade do Vale do Rio dos Sinos (UNISINOS).E-mail: < giv@unesc.net>.

*** Graduada em Serviço Social pela Pontifícia Universidade Católica do Rio Grande do Sul (PUCRS), Especialista e Mestre em Serviço Social pela PUCRS e Doutora em Serviço Social pela PUCRS. E-mail: <mamrocha@unisinos.br>.

**** Pós-doutoranda (UNICAMP). Doutora em Educação (UNISINOS). Mestre em Educação (UNISINOS). E-mail: <marialvamoog@hotmail.com>.
} 
del título extranjero, las diferencias en la formación profesional y la mejoría de inclusión en el mercado laboral. Como retos enfatizan la adaptación a las variaciones lingüísticas y la escritura y la dificultad con contenidos de las que no tenían ninguna base. Revelaron el deseo de regresar a Angola para ayudar a reconstruir el país, que vivió en la guerra civil de 30 años. Los gerentes revelaron conocer las estrategias institucionales de internacionalización, destacando la sostenibilidad y la difusión de las acciones institucionales como forma de dar mayor visibilidad y fortalecer la imagen institucional. Apoyan este proceso acogiendo a los estudiantes y mencionan como valor, las ganancias sociales, culturales y académicas que surge de estas experiencias.

Palabras clave: Internacionalización. Educación Superior. Estudiantes africanos.

\section{INTRODUÇÃo}

São de diferentes naturezas as transformações que estão velozmente ocorrendo nas mais diversas dimensões da vida humana: na economia, na cultura, na política, nas relações de trabalho, nas relações entre produtores e consumidores, enfim, na sociedade em geral, não apenas em âmbito local, mas em âmbito global.

$\mathrm{O}$ atual cenário de internacionalização da educação superior, por exemplo, não emerge do espaço universitário e sim das instâncias econômicas e políticas, conforme apontam Castro e Neto (2012). Para os autores a internacionalização da educação superior é "entendida como uma das formas para que os países em desenvolvimento possam enfrentar os desafios da globalização" (CASTRO; NETO, 2012, p. 73).

O processo de globalização tem impulsionado as políticas de internacionalização do Ensino Superior no Brasil. À mobilidade acadêmica dos estudantes para universidades de países estrangeiros tem se intensificado consideravelmente, assim como aumentou o número de jovens estrangeiros cursando graduação em nosso país, especialmente estudantes africanos e da América do Sul.

Nesse contexto procuramos compreender o processo de internacionalização da educação superior a partir dos estudantes estrangeiros africanos em duas universidades brasileiras e os impactos pessoais e institucionais dele advindo. As questões que orientaram o estudo foram: $\mathrm{O}$ que motivou os estudantes estrangeiros a fazer a graduação no Brasil? Quais os principais problemas e desafios enfrentados pelos estrangeiros africanos? Quais as expectativas desses estudantes com a formação no Brasil? Qual o posicionamento institucional em relação a internacionalização percebido pelos gestores? Como percebem os estudantes estrangeiros na universidade?

A pesquisa teve como lócus a Universidade do Extremo Sul Catarinense - UNESC, localizada em Criciúma, no estado de Santa Catarina e a Universidade do Vale do Rio dos Sinos - UNISINOS, situada em São Leopoldo, no estado do Rio Grande do Sul, escolhidas de forma intencional pelo vínculo dos pesquisadores com as mesmas e pelo número significativo de estudantes africanos que estudam nessas Instituições.
Trata-se de uma pesquisa de cunho exploratório com abordagem qualitativa na qual foi utilizado, para a coleta de dados, o questionário com os estudantes estrangeiros africanos e a entrevista semiestruturada com os gestores das duas Universidades. O universo de estudantes africanos nas duas instituições é de 250 (duzentos e cinquenta), sendo que 107 (cento e sete) deles responderam o questionário no ano de 2015. Dos que responderam o questionário 102 (cento e dois) são da Angola, 03 (três) são da República Democrática do Congo e 02 (dois) são de Cabo Verde. Participaram das entrevistas 19 gestores das duas Universidades, sendo coordenadores de cursos de graduação, de relações internacionais e diretores de centro.

Os dados empíricos, após organizados em quadros de análises e corpus do estudo, foram interpretados à luz dos princípios da Análise de Conteúdo.

O termo "às avessas" no título foi utilizado com o significado de indicar um movimento contrário ao que hegemônica e historicamente aconteceu e ainda acontece, pois, o mais comum era e ainda são os brasileiros se deslocarem para a Europa ou Estados Unidos em busca de uma formação qualificada em nível superior.

Este texto inicialmente aborda os conceitos de globalização e internacionalização e seus impactos nas políticas públicas de educação superior e nas universidades. Adentra, posteriormente, nas análises e interpretações dos dados empíricos à luz do referencial teórico, dando voz aos estudantes estrangeiros africanos, visando compreender os motivos e desafios apresentados por eles a partir da experiência no Brasil e, por fim, apresenta as contribuições dos gestores com o intuito de compreender o posicionamento das duas Instituições em relação à internacionalização.

\section{POSSÍvEIS RELAÇÕES ENTRE GLOBALIZAÇÃO E INTERNACIONALIZAÇÃO DO ENSINO SUPERIOR}

Em nenhum momento anterior, na história da humanidade, o desenvolvimento da sociedade dependeu tanto do conhecimento e da informação como o atual, tendo em vista o fenômeno da globalização. Por isso a universidade 
tornou-se um lugar de suma importância no mundo todo, uma vez que historicamente ela tem a responsabilidade da guarda e da produção de conhecimento.

A sociedade de economia global, movida pelas grandes empresas transnacionais, conforme Dias Sobrinho (2014, p. 644), "assegurada financeira, política e ideologicamente pelos organismos multilaterais, é motorizada pelos conhecimentos utilitários potencializados pelas onipresentes tecnologias informacionais". A economia global se alimenta da instrumentalidade do conhecimento e das competências técnicas associadas a ele e impõe à educação superior a incumbência de fortalecer o sistema produtivo e potencializar as riquezas econômicas.

Embora a maior marca da internacionalização tenha sido a da pós-graduação, por meio da pesquisa, a partir da década de 1990, o ensino de graduação passou a sentir a influência da globalização e foi inserido, também, no interesse do panorama internacional, conforme aponta Morosini (2006).

Dias Sobrinho (2005) afirma que o fato de a educação ser categorizada e regulamentada pela Organização Mundial do Comércio - OMC, como um serviço, corrobora para que haja a internacionalização e a comercialização do ensino superior.

Por isso, conforme afirma Morosini (2006, p. 112), as características da educação estão cada vez mais

[...] imbricadas com o processo de globalização e com as determinações oriundas de organismos internacionais multilaterais [...]. Entretanto, é no sistema de ensino superior que se verifica o maior impacto. Isto porque a globalização considera como um dos principais valores o conhecimento, e neste, o advindo de patamares superiores, onde a busca de educação e de certificação continuada se faz presente.

Knight (2004) aponta que o aumento na demanda para o ensino superior, especialmente em países que não dispõem da infraestrutura para atendê-la, ao mesmo tempo em que há capacidade de oferta em outros países e Instituições, principalmente as europeias, impulsiona o processo de internacionalização da educação superior. Esses são motivos que, também, devem ser considerados neste movimento, pois demonstra um alinhamento entre questões econômicas e visão estratégica da internacionalização.

Os motivos que levam à internacionalização são classificados por Knight (2004) em cinco grupos, mesmo reconhecendo que as fronteiras entre eles nem sempre são muito claras. São eles: primeiro grupo é o dos motivos políticos; o segundo grupo é o dos motivos econômicos, pelo viés da sustentabilidade financeira; o terceiro é o das motivações socioculturais; o quarto grupo são os motivos acadêmicos que levam à inclusão da dimensão internacional no ensino e na pesquisa e; o quinto grupo, refere-se aos motivos meramente mercadológicos, de marketing e venda das atividades acadêmicas como produtos.

As motivações de caráter individual apresentadas por Altbach e Knight (2007), também devem ser consideradas, pois destacam o desejo pessoal e individual de estudantes que, mesmo sem bolsas de estudo ou outros tipos de apoio, decidem cruzar fronteiras para estudar por conta própria em outros países, sendo este o caso de um expressivo contingente de estudantes em mobilidade. Neste caso, para os autores "os estudantes, acabam compondo a maior fonte de recursos financeiros para a internacionalização" (ALTBACH e KNIGHT, 2007, p. 5).

Bartell (2003) aponta diversas formas de internacionalização da educação superior e entre elas podemos citar: a presença de estrangeiros e estudantes/ convênios na graduação; o aumento de concessões de pesquisa internacional e projetos internacionais de pesquisa cooperativados; associações internacionais envolvendo consultorias para universidades estrangeiras; universidades privadas com metas internacionais; cooperação internacional e colaboração em conselhos; e o grau de imersão internacional no currículo, entre outros.

Tendo em conta sua abertura ao exterior, as universidades podem ser classificadas em quatro níveis, segundo o autor espanhol Peña (2014): no primeiro nível encontram-se as universidades locais que atraem estudantes de seu entorno (estado, região, cidade). A docência e os textos utilizados são no idioma nacional. O corpo docente provém majoritariamente da mesma região. Sua função principal é a docência e poucos professores realizam pesquisas e alguns publicam em revistas de pouco impacto. Os critérios de contratação e promoção não levam em conta a atividade internacional do professor.

O segundo nível corresponde às universidades nacionais, que possuem prestígio nacional em algumas áreas. Além de estudantes da região, atrai estudantes de todo o país e uma minoria de estudantes estrangeiros. Algumas disciplinas utilizam leituras de textos em inglês ou espanhol, mas raramente são ministradas aulas que não sejam no idioma nacional, com exceção de conferências eventuais. Alguns estudantes, especialmente de pós-graduação, beneficiam-se de oportunidades de intercâmbio. Existem grupos de pesquisa com presença internacional que coexistem com outros de baixa qualidade.

No terceiro nível encontram-se as universidades com projeção internacional, que apostam na educação, na pesquisa e que possam ser competitivas internacionalmente. Espera-se que os estudantes acompanhem aulas na língua inglesa e fomentam-se 
intercâmbios com universidades de outros países. Há uma política de atração de estudantes e professores estrangeiros, especialmente na pós-graduação. Algumas titulações da universidade são bilíngues e estimulam os estudantes a adquirir experiência internacional antes de terminar a graduação. Há uma política de incentivo e apoio à pesquisa e de julgamento dela com critérios internacionais. Os professores são estimulados a realizar o pós-doutorado no exterior e o reconhecimento internacional é uma condição necessária para alcançar o nível acadêmico mais elevado. Estabelecem redes de cooperação e intercâmbio com universidades de outros países.

Por fim, no quarto nível está a universidade que pode ser considerada internacional, onde o ensino em geral é bilíngue ou na língua inglesa. Nela há um número elevado de estudantes estrangeiros nas aulas, tanto na graduação como na pós-graduação, assim como de professores estrangeiros. Espera-se que um bom número de estudantes passe pelo menos um quadrimestre em uma universidade estrangeira antes de concluir a graduação, e um número considerável deles, após concluir a graduação, encontre um trabalho internacional. A maior parte dos seus professores possui experiência em pesquisa internacional, que é valorizada na contratação e na promoção. Estabelecem-se alianças estratégicas de cooperação com universidades internacionais em outros países.

Estes quatro tipos de universidades cumprem um papel fundamental para a sociedade e seria irreal pensar que todas as universidades devem aspirar ao nível quatro. No entanto, alerta Peña (2014), é importante no contexto latino-americano que exista um grupo de universidades internacionais e um bom número de universidades com projeção internacional. Ele chama a atenção para o fato de que alcançar reconhecimento nos primeiros níveis nos rankings internacionais, é motivo de atração de estudantes.

O autor aponta que os jovens estão hoje em dia cada vez mais conscientes das vantagens de uma formação internacional no acesso ao mercado de trabalho, o que resulta no crescimento de estudantes estrangeiros nas universidades.

Por isso a qualidade de ensino passou a ser preocupação nacional uma vez que estudantes de outros países seriam potenciais presenças nas Instituições de Ensino Superior - IES brasileiras. A busca da qualidade da educação superior, também, se potencializou pós o advento da institucionalização dos processos avaliativos internos e externos das Instituições de Educação Superior no Brasil e no mundo.

O Brasil tem sido uma possibilidade valiosa para estudantes estrangeiros, provenientes de países africanos de língua portuguesa, fazerem seus cursos de graduação, em especial, pelo reconhecimento da qualidade do ensino e da produção científica qualificada que dispõe. Para além da facilidade com a língua falada, também a aproximação cultural, uma vez que tanto o Brasil como vários países africanos foram colonizados pelos Portugueses. O Brasil tem forte influência dos costumes africanos, pois foram muitos os africanos trazidos para o país no período colonial.

Um dos países africanos que tem demonstrado uma forte relação histórica e cultural com o Brasil é Angola. A Secretária de Estado da Angola Ângela Bragança (2015, p. 13) ao se referir ao passado colonial e a escravatura em comum, assim se referiu:

\begin{abstract}
estas criaram laços indestrutíveis entre os respectivos povos, base para uma relação forte, interativa e consistente que forjou o respeito, a amizade e proporcionou à cooperação um sentido estratégico, definida na Declaração de Parceria Estratégica aprovada pelos órgãos de soberania.
\end{abstract}

Da mesma forma afirmou que os angolanos residentes no exterior "são como 'embaixadores' da cultura e identidade do povo, suas bandeiras vivas e portas estandarte do orgulho, do prestígio e também da sua grandiosidade e firmeza" (BRAGANÇA, 2015, p. 13).

Tendo apresentado os referenciais teóricos e os intensões deste estudo passamos a apresentar os resultados da presente pesquisa.

\section{ESTUDANTES AFRICANOS NA UNESC E UNISINOS: O QUE REVELOU A PESQUISA}

Os primeiros estudantes africanos na Unesc vieram em 2006, com bolsa integral de estudos e demais despesas custeadas por meio de um convênio com a Petrolífera Angolana Sonangol, segundo os gestores entrevistados, o que também caracteriza uma das diversas formas de internalização apontadas por Bartell (2003).

Atualmente, o maior número de estudantes estrangeiros da Unesc, foi selecionado por edital para estrangeiros. Ao ser aprovado, o estudante arca com os custos totais da formação, pagando as mensalidades, uma vez que a Instituição, mesmo sendo comunitária, é de direito privado e pressupõe o pagamento de anuidade.

$\mathrm{Na}$ Unisinos, que também é uma Instituição comunitária de direito privado, o candidato participa de edital de seleção e recebe uma bolsa de estudos da Sonangol para cursar a graduação, em áreas de interesse da própria estatal, que subsidia o aluguel de imóvel, alimentação, locomoção, aulas de inglês entre outros.

A gestora das relações internacionais assim se expressou, esclarecendo o programa na Unisinos: 


\begin{abstract}
"tem a petrolífera angolana que é a SONANGOL que é estatal que banca esse programa para os estudantes que vem para o Brasil. Tem uma empresa brasileira que faz todo o trabalho de organização da vinda dos estudantes, e aí essa empresa que fez o acordo com a Unisinos. Eles são isentos do vestibular, porque eles já passaram por todo o processo seletivo lá, aí eles fazem todo o curso aqui."
\end{abstract}

Dados do questionário apontam certa resistência por parte de alguns estudantes africanos em vir estudar no Brasil, principalmente pelas informações sobre violência que recebiam em seu país.

\begin{abstract}
"a gente via Globo e Band e 90\% das informações eram de assassinato, guerra entre quadrilhas. Eram novelas e nossos pais não nos deixavam olhar novelas brasileiras, pois consideravam que tinha muita nudez. Mas em termos acadêmicos acho que estou em um bom país, principalmente em uma boa universidade".
\end{abstract}

Alguns estudantes africanos, em seus depoimentos, demonstraram relutância inicial em ficar no Brasil apresentando como justificativa o entendimento de que em muitos aspectos o Brasil é parecido com a Angola e queriam algo diferente. De alguma forma a percepção dos estudantes a respeito do Brasil, também, pode ser entendida como consequência do processo de internacionalização.

Com o objetivo de organizar a apresentação dos resultados do estudo foi elaborado seis dimensões explicativas: Motivos da escolha do Brasil; Acolhimento Institucional; Problemas e desafios pessoais; Perspectivas a partir da experiência de formação no exterior e; Percepção dos gestores sobre a internacionalização na Instituição.

\section{Motivos DA ESCOLHA Do BRASIL}

Como primeira dimensão do estudo, o Quadro 1 apresenta em síntese as variações e intensidade dos principais motivos apontados, pelos nossos interlocutores de fazer sua formação no Brasil.

Quadro 1. Motivos da escolha por estudar no Brasil ${ }^{1}$

\begin{tabular}{lcc}
\hline \multicolumn{1}{c}{ Motivos } & No de estudantes & \% \\
\hline Qualidade do ensino e da formação & 78 & 72,9 \\
Conhecer novas culturas e pessoas & 23 & 21,0 \\
Valorização do diploma estrangeiro & 12 & 11,2 \\
Melhoria no emprego & 10 & 9,3 \\
Maior opção de cursos & 08 & 7,4 \\
Influência familiar & 04 & 3,7 \\
Oportunidade de bolsa de estudo & 03 & 2,8 \\
\hline
\end{tabular}

Fonte: Elaborado pelos autores.

\footnotetext{
${ }_{1}$ Por conter perguntas abertas os estudantes se manifestaram livremente, por isso o número total de respostas não condiz com o número de respondentes.
}

Como podemos observar os estudantes estrangeiros africanos mencionaram a qualidade de ensino e formação (78) no Brasil como o principal motivo para a sua vinda.

\begin{abstract}
"o que me motivou estudar no Brasil foi a qualidade de ensino e a qualidade na formação profissional. Também a vontade de estudar e viver fora por um tempo conhecer outro país, outro povo, hábitos e costumes, o dia-a-dia, a gastronomia, tudo aquilo que forma um país".
\end{abstract}

O depoimento acima sinaliza o segundo motivo (23) apresentado pelos estudantes que é a possibilidade de conhecer novas culturas e pessoas, o que também impulsiona os jovens a buscarem uma formação no exterior.

A valorização do diploma estrangeiro (12) foi apontada pelos estudantes africanos, e a maioria deles alia a melhoria de oportunidade, relacionando o diploma à possibilidade de melhoria no emprego (9). "O diploma de um país estrangeiro tem mais peso e aí consigo encontrar um emprego com maior facilidade". Este depoimento nos remete a Peña (2014) quando afirma que os jovens estão cada vez mais conscientes sobre as vantagens de uma formação internacional para ter acesso ao mercado de trabalho.

Um dos estudantes questiona a desvalorização das universidades africanas:
“as nossas universidades não são reconhecidas. Não sei por que e já tem muito tempo de história e já formou vários líderes africanos e de outros lugares que iam para lá, mas até agora não é reconhecida. Não sei se é o fraco orçamento que disponibilizam para a área da educação...Então é isso que faz a maioria dos estudantes querer sair do país para estudar fora”.

Realmente nos rankings mundiais não há países africanos e ainda nos rankings das universidades africanas, não consta nenhuma universidade angolana.

Dependo da especificidade e do curso que frequentam os estudantes apontaram, também, como motivo o fato de que no Brasil há maior opção de cursos (8) de graduação. Um estudante disse: "primeiro pelos variados cursos existentes, pela extensão da escolha e pelo que pode ser feito com o curso que escolhi".

A influência familiar (4) também foi apontada como decisivo para quatro deles vir estudar no Brasil. Bourdieu (1996) já havia apontado a influência da família nas escolhas dos jovens em momentos de decidirem o curso, a instituição e a profissão a seguir. A decisão e a motivação tornam-se ainda mais forte quando se vislumbra uma oportunidade de bolsa de estudos (3). O depoimento abaixo contém os dois motivos: 


\begin{abstract}
"A pessoa que me motivou foi a minha mãe. Ela me encaminhou a empresa que estava a dar bolsa de estudos para fora do país e quando ganhei a bolsa a minha preferência foi estudar no Brasil e aqui estou eu na Unesc".
\end{abstract}

Importante também destacar que os pais ou familiares que possuem curso superior, tendem a incentivar direta ou indiretamente seus filhos ou parentes a seguirem seus estudos.

Do total dos estudantes estrangeiros pesquisados, ou seja, 107 (cento e sete) somente 7 (sete) deles responderam no questionário que ninguém da família possui formação em nível superior. Isto também demonstra que neste universo os estudantes se originam de famílias que têm nível superior, portanto poucos são estudantes de primeira geração.

Para muitas famílias, conforme Bourdieu (1996) a escolha da profissão constitui-se uma via de reprodução social e cultural, sobretudo para aquelas onde os pais são profissionais em exercício da mesma profissão. Segundo o autor, a família assume um papel determinante na manutenção da ordem social e na reprodução das relações sociais. É um dos lugares por excelência de acumulação das diferentes espécies de capital e de sua transmissão entre as gerações.

Estudos realizados por Mercado (2004) também demonstraram a força da família na definição da escolha do curso de graduação e da futura profissão em adolescentes. A autora aponta como os pais intervêm usando estrategicamente seus recursos sociais para convencer os jovens a seguirem determinadas profissões ou avalizarem suas decisões. Os jovens ficam com poucas chances de reverter 'o jogo' em que estão envolvidos.

\section{ACOLHIMENTo InstitucionaL}

A segunda dimensão do estudo refere-se ao acolhimento institucional, a forma como foram recebidos pela universidade, mas, também, pelos professores e colegas brasileiros.

A grande maioria dos estudantes africanos (98), disse ter sido bem recebido pela Instituição, o que pode ser facilmente evidenciado pelas muitas manifestações neste sentido. "Tive um bom acolhimento por parte da Instituição. A recepção foi ótima"

$\mathrm{Da}$ mesma forma 87 (oitenta e sete) estudantes deixaram registrado no questionário que se sentiram bem acolhidos pelos professores. Percebemos que os estudantes africanos se manifestaram favorável ao modo como foram recebidos pelos demais colegas da turma. "Fui recebido pelos professores e pelos colegas brasileiros de uma forma muito especial carinhosa e acolhedora".
No entanto alguns depoimentos sinalizaram que houve um processo de assimilação e aceitação às regras do jogo, de negociação e reconstrução diária de elementos indenitários do país de origem, a fim de se adaptarem a nova realidade sociocultural. "A recepção em geral foi boa, não muito pelos professores porque notei que não estão acostumados a trabalhar com estrangeiros $e$ eu tive que me adaptar com a forma de vocês, para me enquadrar".

$\mathrm{Na}$ entrevista os coordenadores de curso, os gestores de unidades acadêmicas e os responsáveis pelas atividades de relações internacionais destacaram que as Instituições se preparam para este momento de recepção, com cerimônias especiais de apresentação e acolhimento a estes estudantes. Reconhecem que os estudantes estrangeiros merecem uma atenção especial e apoio ao iniciar sua graduação longe do país de origem, mas sabem, também, que estudantes estrangeiros são importantes para a sustentabilidade da instituição e mantê-los satisfeitos é uma condição importante.

A gestora de Relações Internacionais de uma das Instituições confirma a importância da vinda dos alunos estrangeiros para a Universidade dentro da proposta de internacionalização.
"é mais importante a gente ter estudante estrangeiro regular do que estudante de mobilidade porque o regular é que interage, traz a cultura dele para dentro da universidade e leva depois o conhecimento que ele adquiriu aqui para o país de origem. Inclusive para rankings internacionais é muito importante que a Universidade tenha estudantes regulares estrangeiros. Então os angolanos são fundamentais para o nosso projeto de internacionalização".

No entanto 10 (dez) estudantes relataram que não se sentiram bem acolhidos pelos colegas da turma e relataram suas percepções e sentimentos. "Por parte dos colegas houve certo grau de indiferença e sarcasmos".

\footnotetext{
"quando recebíamos estudantes de Portugal nós ficávamos com bastante curiosidade de saber de onde vinham, o que vinham a cá fazer, como vieram a cá parar e tudo mais, mas o que nós fazíamos era ir até eles, tinha aquele interesse, fazíamos amizades. Mas aqui, na sua maioria, há uma falta de interesse, há curiosidade, mas há falta de interesse do pessoal".
}

Isto pode ocorrer porque os estudantes brasileiros não reconhecem os colegas como sendo angolanos, pois podem pensar que são brasileiros por suas características físicas e por falarem a mesma língua. Também, há o fato de que o sistema curricular das Instituições não favorece a organização de estudantes estrangeiros em turmas, pois cada estudante pode escolher as disciplinas 
que vai cursar na matriz curricular de forma variada, dificultando os vínculos. São também, em sua maioria, estudantes trabalhadores que vem para a aula a noite e logo voltam para casa, sem tempo para outras atividades na Universidade.

\section{Problemas e desafios Pessoais}

São vários os problemas e desafios pessoais enfrentados por eles desde a chegada e durante todo o tempo de estada no Brasil, para poder concluir o curso de graduação. No questionário tiveram liberdade de se expressarem e nos seus depoimentos foi possível elaborar algumas categorias que se apresentam no Quadro 2.

Quadro 2. Problemas e desafios pessoais

\begin{tabular}{lcc}
\hline \multicolumn{1}{c}{ Problemas/desafios } & o de estudantes & \% \\
\hline Racismo e discriminação social & 32 & 30 \\
$\begin{array}{l}\text { Metodologia, conteúdo e relação } \\
\text { professor/aluno }\end{array}$ & 31 & 29 \\
Linguagem e escrita & 17 & 16 \\
Questões financeiras & 14 & 13 \\
Cultura e costumes & 13 & 12 \\
Saudade da família & 11 & 10 \\
\hline
\end{tabular}

Fonte: Elaborado pelos autores

O problema e desafio a ser enfrentado, mais citado pelos estudantes, foi racismo e discriminação social (32). Aparecem nos depoimentos tanto de forma clara como de forma velada, sutil, percebida por eles. "O maior desafio talvez seja o racismo silencioso das pessoas que talvez seja por ignorância".

De certa forma os alunos demonstram através de seus depoimentos que o desconhecido para grande parte da população, muitas vezes é rechaçado. Ressaltam o viés preconceituoso existente na sociedade e a dificuldade de receber alguém que é de outra cultura, principalmente daqueles que vêm da África. Os alunos angolanos comentaram sobre sua surpresa ao perceberem que os brasileiros desconhecem completamente o continente africano e confundem o mesmo como sendo um único país. Isto pode revelar a causa, também, da desconfiança por parte da população. Uma estudante assim se manifestou:

\footnotetext{
"algumas vezes, por parte de alguns brasileiros, a gente tem sofrido preconceito racial. Algumas vezes, nas paradas de ônibus, temos sofrido isso, não por parte de todos, mas de alguns dos motoristas que quando vêm que há apenas negros na parada, eles nem sequer param o ônibus".
}

Um dos depoimentos no questionário mostra o grau de discriminação sentida por eles em alguns momentos em sala de aula: "Em trabalhos em grupos sentia muito receio, pois parte dos colegas fugiam em trabalhar com angolanos porque acham que não sabemos nada". Além disso, o sentimento que aflora a partir desta constatação ficou expresso nesta manifestação: "pensar em racismo é algo que doí lá dentro".

Parafraseando Sousa Santos (2003) as pessoas têm direito à igualdade sempre que a diferença as tornar inferiores, mas têm direito à diferença sempre que a igualdade ameaçar suas identidades.

Os estudantes não se davam conta de que eram diferenciados pela população por serem negros, até chegar ao Brasil, especialmente na região sul, uma vez que em Angola não há diferença, pois, a população, em geral, é negra. Talvez o impacto não tivesse sido o mesmo em cidades do nordeste brasileiro, onde a maioria da população é autodeclarada parda ou negra, diferente das cidades onde se localizam as Instituições, lócus desta pesquisa. Criciúma, em Santa Catarina, fundada por imigrantes italianos e São Leopoldo, no Rio Grande do Sul, cidade "berço da colonização alemã".

Embora parte significativa dos estudantes africanos tenham sentido a discriminação e pré-conceito, a maior parte dos gestores das Instituições demonstra estar atento a esta questão e mencionaram "eu valorizo as trocas de culturas e oportunidades de crescimento mútuo, por meio do convivio entre alunos estrangeiros e brasileiros". Um dos coordenadores de curso assim se expressou:

\footnotetext{
"á uma coisa muito boa que é a troca de experiências, principalmente com a vinda dos angolanos. Os brasileiros interagindo, perguntando sobre a cultura do país deles. Eu gosto disso. Quando não se conhece ficam com uma visão das coisas da mídia, criam-se tabus e preconceitos por falta de conhecimento e de educação".
}

O coordenador admite que há racismo, mas busca valorizar a troca de culturas e o convívio em sala de aula. Segundo Mwewa (2009), a igualdade só acontecerá de fato quando houver uma relação, entre os sujeitos pares com as mesmas características sociais, físicas e econômicas. Do contrário tende a resultar em um processo de diferenciação. A instituição escolar terá sempre um papel fundamental no desenvolvimento das relações de igualdade. É nela que os sujeitos iguais e diferentes se encontrarão e se compreenderão com mais facilidade. São essas diferenças que permitirão analisar quem é igual e quem é diferente, ou seja, a partir desses intercâmbios surgirão os conflitos, as diferenças, as negociações e os diálogos, e fundamentalmente, o respeito.

Os estudantes demonstraram certa dificuldade em relação à metodologia, conteúdo e relação professor aluno, desenvolvido no Brasil e tiveram que se adaptar. 
O ensino no Brasil é visto pelos estudantes como sendo mais prático, já em Angola mais teórico. Revelam que precisaram se adaptar com a perspectiva de aprender por meio de projetos de pesquisa e extensão, pois essas práticas proporcionam um aprendizado melhor porque insere o estudante na prática de fato.

$\mathrm{Na}$ perspectiva dos estudantes angolanos, os professores brasileiros passam os conteúdos mais detalhadamente, fato que consideram positivo. Em Angola o professor não sintetiza os conteúdos para o aluno fazendo que eles pesquisem mais. Em relação a dificuldades com conteúdos eles se referem principalmente aos que são oriundos de políticas públicas e de leis próprias do Brasil.

“o principal desafio no âmbito acadêmico foram os temas relacionados com o Brasil, mais precisamente com as disciplinas como a contabilidade tributária, que trata de tributos do Brasil. São assuntos de extrema complexidade e exigiram de mim um esforço maior para poder compreender".

Os estudantes, em geral, destacaram a forma como o professor relacionar-se com o aluno. A liberdade que o professor proporciona ao aluno para dialogar com ele durante as explicações é destacada como ponto positivo da educação brasileira, no entanto, apresentam como problema ou desafio aceitar a falta de respeito com o professor e com os colegas como aspecto que prejudica o andamento das aulas.

Embora a maior parte dos estudantes africanos falem a língua portuguesa, a linguagem e escrita, muitas vezes se constitui como um problema a ser enfrentado pelos estudantes. "O principal desafio que tenho enfrentado é a comunicação. Apesar de falarmos a mesma língua, alguns termos que são empregados aqui são desconhecidos para muitos de nós".

Embora Brasil e Angola tenham o mesmo idioma oficial, há diferenças na comunicação que demandam certas adaptações, pois são os atos linguísticos e os demais elementos da cultura de cada povo que diferem e definem sua identidade nacional. É por meio da linguagem, também, que as relações de significação são entendidas e dão sentido à realidade. Portanto a estrutura da linguagem é instável, ela balança dependendo do contexto e dos sujeitos envolvidos. Assim, foi possível detectar nos depoimentos, algumas diferenças existentes. É por meio do ato da fala, fundamentalmente, e da escrita que se percebe a identidade e a diferença de cada indivíduo ou grupo. Elas precisam ser ativamente produzidas. A língua nada mais é do que um "sistema de diferenças" segundo Silva (2005, p. 77-78).

Para os estudantes da República Democrática do Congo, cujo idioma é o Francês, a dificuldade é muito maior, por isso a Instituição tem ofertado cursos gratuitos de Português para Estrangeiros por meio do Curso de Letras, segundo uma das gestoras entrevistadas.

As questões financeiras, também, aparecem como sendo um dos problemas que os alunos dos países africanos enfrentam no Brasil, principalmente por aqueles que não possuem nenhum tipo de subsídio para custear as despesas de mensalidades, alimentação, transporte e moradia. "A verdadeira dificuldade é a questão financeira, a falta de subsídios que se traduz na falta de alguns pagamentos, como é o caso das propinas ${ }^{2}$ da universidade e do aluguel. De uma forma ou de outra acaba por afetar o rendimento do estudante".

Do total de estudantes que responderam o questionário 66 subsidiam com recursos próprios ou de familiares as despesas com a formação no Brasil. Como apontado por Altbach e Knight (2007), parece que muitos deles decidem atravessar fronteiras por conta própria, por desejo pessoal e motivação individual, sem bolsas de estudo ou outro aporte financeiro.

Embora conhecer uma nova cultura e costumes tenha sido apontado como motivador para cursar uma graduação fora do país, também pode ser considerado um problema para alguns deles, que apontam esse desafio: "cultura, modos diferentes de encarar muitas coisas. No começo foi realmente, bastante difícil por causa do processo de adaptação à realidade contextual, naquilo que é a diferença cultural dos dois países".

Da mesma forma alguns estudantes relataram que acham o comportamento das pessoas muito "aberto" fazendo referência à falta de limites dos jovens. Ao mesmo tempo trazem os costumes da sociedade angolana que neste aspecto, atualmente, talvez por questões legais, se difere da sociedade brasileira.

"lá (na Angola) o pai do vizinho ou qualquer pessoa que seja adulto, mesmo que não seja adulto, que flagra um filho do vizinho fazer algo desse tipo, tem todo direito de repreender e chegar até a casa e expor o que aconteceu e até mesmo dar uns puxões de orelha”.

A saudade familiar também é considerada pelos estudantes como um problema ou desafio a enfrentar. "é claro que estudar fora do nosso ceio familiar não
é fácil. Termos que nos deparar com as dificuldades
do cotidiano e geralmente as pessoas que nos ajudam
a ultrapassar estão distantes. Estudar fora nos
obrigar a crescer de uma hora para outra, porque já
não tens mais a mãe para passar a mão nos nossos
erros".

\footnotetext{
2 Em Angola, o valor a ser pago pelo curso que é dividido em parcelas mensais, cada parcela ou prestação, é chamada de propina.
} 
Apesar dos problemas e desafios enfrentados, os estudantes africanos continuam nas instituições e apresentam perspectivas importantes no retorno ao país de origem.

\section{Perspectivas A PARTIR dA EXPERIÊNCIA DE FORMAÇÃO NO EXTERIOR}

Perguntamos aos estudantes sobre as perspectivas que tinham ao retornar ao país de origem, a partir da formação obtida no Brasil, pois sabemos que os mesmos têm visto de permanência apenas no período em que estão cursando a graduação. Significativo número de estudantes demonstrou ter um compromisso muito grande com o seu país, com sua reconstrução e desenvolvimento, pois como pode ser percebido no Quadro 3, a aplicação dos conhecimentos adquiridos na reconstrução do país foi o que mais apareceu como resposta no questionário.

Quadro 3. Perspectivas a partir da experiência de formação no exterior

\begin{tabular}{lcc}
\hline \multicolumn{1}{c}{$\begin{array}{c}\text { Perspectivas a partir da } \\
\text { formação }\end{array}$} & $\mathbf{N}^{\mathbf{0}}$ de estudantes & \% \\
\hline $\begin{array}{l}\text { Aplicação dos conhecimentos } \\
\text { adquiridos na reconstrução do país }\end{array}$ & 48 & 45 \\
$\begin{array}{l}\text { Crescimento e reconhecimento } \\
\text { pessoal }\end{array}$ & 29 & 27 \\
$\begin{array}{l}\text { Melhoria de oportunidade no } \\
\text { mercado de trabalho }\end{array}$ & 27 & 25 \\
\hline
\end{tabular}

Fonte: Elaborado pelos autores.

Um dos estudantes disse: "após a minha formação espero retornar mais capacitado para suprir com as necessidades e ajudar o meu país a se desenvolver".

Outro estudante acrescenta:

"por motivos óbvios. Angola acabou de sair de uma guerra que predominou por 30 anos, e consequentemente estamos em 10 anos de paz. Nesta ordem de ideia quero me profissionalizar para contribuir na reconstrução do meu país".

Os estudantes angolanos parecem estar conscientes de que acima das questões individuais precisam voltar para ajudar no desenvolvimento e crescimento de Angola, que durante trinta anos esteve em guerra civil, após sua independência de Portugal, ocorrida em 1975. Esses jovens demonstram perceber sua importância na reconstrução do país que foi mutilado e ficou basicamente estagnado durante a guerra civil após a independência.

Os gestores corroboram com tal percepção e procuram fundamentar o motivo que fez a Petrolífera Sonangol firmar os convênios com universidades estrangeiras para formação profissional dos angolanos.

\begin{abstract}
"eles vêm por um projeto do governo de Angola de desenvolvimento de recursos humanos. Eles mandam estudantes para vários países. Penso que o governo precisa de talentos muito rápido, até o sistema de educação deles se desenvolver até o nível do brasileiro ou ainda mais, chegar no nível do Inglês. O tempo está passando, então eles devem estar investindo na formação de talentos para desenvolver o país".
\end{abstract}

Um número significativo de estudantes se referiu ao crescimento e reconhecimento pessoal (29) como a maior expectativa ao retornar ao país de origem. "Espero que o meu retorno ao meu país seja de uma forma concretizada, ou seja, vitorioso por ter cumprido o que realmente me trouxe para cá, que é a minha formação superior e profissional".

Da mesma forma a expectativa do retorno para um bom número de estudantes é que tenham melhoria de oportunidade no mercado de trabalho (27). "O $\mathrm{Oeu}$ retorno espero que seja bastante motivador para minha profissão e que eu arranje um bom emprego".

\section{PERCEPÇÃo dOS GESTORES SOBRE A INTERNACIONALIZAÇÃO E OS ESTUDANTES AFRICANOS NA INSTITUIÇÃO}

As estratégias e ações nas duas Instituições pesquisadas deixam claro o posicionamento favorável e proativo de fortalecimento da internacionalização, percebido pelos 21 (vinte e um) gestores, participantes da pesquisa. As questões apontadas foram sintetizadas no Quadro 4.

Quadro 4. Posicionamento da Instituição em relação a internacionalização

\begin{tabular}{lcc}
\hline \multicolumn{1}{c}{$\begin{array}{c}\text { Estratégias de internacionalização } \\
\text { da IES }\end{array}$} & $\begin{array}{c}\text { No de } \\
\text { gestores }\end{array}$ & \% \\
\hline $\begin{array}{l}\text { Divulga as ações de internacionalização no } \\
\text { site da universidade e nos jornais da região }\end{array}$ & 08 & 47,0 \\
$\begin{array}{l}\text { Firma convênios com instituições estrangeiras } \\
\begin{array}{l}\text { Incentiva a participação no Programa Ciência } \\
\text { sem Fronteiras }\end{array}\end{array}$ & 08 & 47,0 \\
$\begin{array}{l}\text { Fortaleceu o Setor de Relações Internacionais } \\
\text { Possui uma história de internacionalização }\end{array}$ & 07 & 41,0 \\
com Angola & 07 & 41,0 \\
$\begin{array}{l}\text { Lança edital de processo seletivo para } \\
\text { estrangeiros }\end{array}$ & 04 & 25,5 \\
$\begin{array}{l}\text { Criou e aprovou políticas para } \\
\text { internacionalização }\end{array}$ & 04 & 25,5 \\
$\begin{array}{l}\text { Participa do programa de mobilidade } \\
\text { acadêmica Santander Universidades }\end{array}$ & 04 & 25,5 \\
$\begin{array}{l}\text { Adequou-se as exigências de avaliação do } \\
\text { MEC/CAPES }\end{array}$ & 03 & 17,5 \\
$\begin{array}{l}\text { Prepara os estudantes e professores em inglês } \\
\text { Internacionalização é meta no planejamento } \\
\text { estratégico }\end{array}$ & 02 & 11,5 \\
$\begin{array}{l}\text { Firmou convênio para dupla certificação na } \\
\text { graduação com IES estrangeira }\end{array}$ & 02 & 11,5 \\
\hline
\end{tabular}

Fonte: Elaborado pelos autores. 
Percebe-se que há interesse das Instituições em divulgar as ações e atividades de internacionalização, provavelmente por constituir-se em um valor que oferece prestígio a própria universidade. Da mesma forma os gestores demonstraram possuir conhecimento sobre os convênios de cooperação entre a Universidade e outras IES estrangeiras.

O Programa Ciência sem Fronteiras, de mobilidade acadêmica, oferecido pelo governo federal, também tem movimentado as instituições, na percepção dos gestores, inclusive um deles cita o fato de haver cursos de inglês para preparação dos estudantes.

Percebe-se, também, que o fortalecimento do setor de relações internacionais foi citado pelos gestores com a mesma intensidade que a histórica relação de internacionalização com a Angola. Provavelmente com a chegada de número significativo de angolanos a IES teve que adequar o setor as novas demandas vislumbrando uma expansão futura. Um dos gestores explica que:

“a UNESC tem uma história de internacionalização com a Angola, e a partir de Angola a gente tem outros países daquela região que passam a estar mais presentes aqui na UNESC. Isso tem sido um movimento importante, do ponto de vista inclusive social".

Os gestores também demonstraram ter conhecimento sobre editais de processos seletivos para estudantes estrangeiros bem como a aprovação de políticas institucionais de internacionalização.

O movimento de internacionalização das IES foi apontado por dois gestores como um processo necessário de adequação as exigências da avaliação da Educação Superior.

\footnotetext{
"a gente sempre tinha entendido que o movimento de internacionalização é muito mais forte no campo da pós-graduação, porque ele acaba sendo um elemento de avaliação importante nos programas stricto sensu. A medida que a gente tem programas e quer subir o conceito e dar visibilidade aos quadros que têm, trazer mais interessados para fazer o mestrado e doutorado, qualificar e cumprir com o papel de desenvolvimento regional, a gente tem que olhar para esses parâmetros de avaliação".
}

Essa é uma percepção forte uma vez que, conforme Morosini (2006, p. 108), "a universidade sempre teve como norma a internacionalização da função pesquisa, apoiada na autonomia do pesquisador".

Também apareceu como estratégias e ações o fato de as IES participarem do programa de mobilidade acadêmica Santander Universidades e de ter firmado recentemente um convênio para dupla certificação no curso de graduação em Design com uma IES estrangeira.

De modo geral os gestores veem de forma muito positiva esse movimento provocado pela internacionalização e demonstraram isso na entrevista.

\begin{abstract}
"eu entendo que é algo bastante positivo. A gente percebe que todas as universidades do mundo estão caminhando nesse sentido. Esses intercâmbios de ideias, de pessoas de países diferentes, com outras culturas, com outros costumes que vem se integrando nesse mundo globalizado. E aqui na universidade também não é diferente. Muito embora, nós temos, quase que exclusivamente, angolanos aqui na Instituição".
\end{abstract}

O que foi percebido com a pesquisa é que há um movimento de crescimento das relações internacionais nos vários sentidos, como assinatura de convênios de cooperação, elaboração de editais para seleção de estudantes estrangeiros, participação em programa de mobilidade acadêmica, aulas de inglês pontuais de preparação para os estudantes, o que, pelas características apresentadas, em termos de abertura ao exterior, dentre os quatro níveis apontado por Pena, pode ser classificada como nível dois.

\section{CONSIDERAÇõES FINAIS}

A pesquisa indica que os estudantes angolanos vêm estudar no Brasil pela oportunidade de uma bolsa de estudos e mesmo os pagantes, consideram que o diploma estrangeiro tem maior reconhecimento no seu país. Os estudantes encontraram desafios no âmbito acadêmico, como adaptação às variações linguísticas e de escrita da Língua Portuguesa e dificuldades com alguns conteúdos que exigem uma base mais consistente de estudos iniciais. Além disso, percebem diferenças na metodologia de ensino, principalmente na forma como os professores expõe o conteúdo e procuram relacionar com a prática, além de apontarem como positiva a relação horizontal professor/aluno. Apontam que tiveram que enfrentar muitos problemas e desafios de ordem pessoal, como estar longe da família, dificuldades financeiras, o clima, a falta de aproximação dos brasileiros, o medo da violência no Brasil e o racismo, ainda presente na nossa sociedade. Mas reconhecem que a formação acadêmica no Brasil favorecerá sua inclusão no mercado de trabalho em Angola, pois lhes proporciona um diferencial profissional.

Chama a atenção, nos dados obtidos, que os estudantes angolanos são unânimes em afirmar sua pretensão de voltar para a Angola para ajudar a reconstruir o seu país, após trinta anos de guerra. Percebe-se, através de seus depoimentos descritos no questionário, que há 
uma consciência política relacionada aos compromissos coletivos, além dos interesses individuais.

Sua inserção nas IES brasileiras vai ocorrendo paulatinamente. Como em outros contextos estudados, percebe-se que as comunidades estrangeiras são mais coesas e que nem sempre os nativos interagem academicamente com eles. Assim as práticas de ensinar e aprender nas universidades locais, ainda demonstram uma escassa abertura para o "outro", como se a obrigação da integração fosse apenas do que chega. Provavelmente, com a ampliação da cultura da internacionalização esse fenômeno possa se alterar, pois atingirá uma meta mais solidária e cosmopolita, alcançando, como afirma Sousa Santos (2001), uma reconfiguração de saberes.

Entretanto, é inegável que a presença desses grupos de estudantes africanos, de distintos hábitos e culturas impactam positivamente as universidades brasileiras. É inevitável que nos rituais de ensinar e aprender vão se instalando processos comparativos e de intercultural idade. As IES aprendem com esse público e podem, de alguma forma, avaliar, também, a experiência dos alunos brasileiros que se deslocam para o estrangeiro. Pouco a pouco vão criando estratégias de acolhimento e inclusão que aliam movimentos tantos de internacionalização como de democratização.

Os docentes são instados a certos deslocamentos de seus saberes, instigados por uma saudável curiosidade dos estudantes que chegam. Eles encontram um especial espaço de vivência de cidadania, e podem estimular a valorização da diferença sempre que esta signifique, como indica Sousa Santos (2001), uma condição para a igualdade.

Os dados nos fazem inferir que os estudantes brasileiros são beneficiados por este convívio, pois principalmente por se depararem com colegas com um compromisso social muito explícito. Têm a oportunidade de um exercício de cidadania que contribui para seu futuro profissional.

Os depoimentos dos gestores desvelaram a preocupação dos mesmos em apoiar todo este processo, recebendo os estudantes estrangeiros, mas também "cuidando" para que tenham sentimentos de acolhimento e proteção que, consequentemente, lhes farão permanecer até a conclusão dos seus cursos de graduação.

$\mathrm{Na}$ entrevista demonstram conhecer as estratégias institucionais de internacionalização e destacam divulgação das ações institucionais como forma de dar maior visibilidade e fortalecer a imagem institucional, assim como mencionaram os diversos convênios assinados com universidades estrangeiras.

Alguns destacam o fato de os angolanos serem alunos regulares, que frequentam o curso todo, não apenas como intercambistas, e que este é um nicho de sustentabilidade significativo uma vez que a instituição alcança outro público que não está na concorrência dos seus limites geográficos. Da mesma forma mencionam como valor os ganhos sociais, culturais e acadêmicos advindos dessas experiências, o que evidencia que as fronteiras entre uma razão e outra da internacionalização nem sempre são claras, como foi apontado por Knight (2004).

Deixaram claro que acompanham e incentivam a participação dos jovens no Programa Ciência sem Fronteiras, mas destacam a histórica relação de internacionalização com Angola. Percebem que a internacionalização é um caminho sem volta e que por isso a Instituição vem fortalecendo o setor de relações internacionais. Da mesma forma alguns deles mencionam que as intensificações das ações de internacionalização são impulsionadas pela avaliação CAPES/MEC.

Certamente há muitos desafios e contradições nesse processo. Nossa expectativa é que as investigações, como a que ora desenvolvemos, possam contribuir para a condição da qualidade acadêmica que envolve democratização e internacionalização.

Parece improvável que esses processos possam ser detidos. E nem temos como saber ainda, de forma mais completa, sobre seus efeitos sobre os países e os indivíduos. Em princípio a mobilidade oportuniza a interação sócio cultural e agrega importantes experiências para os indivíduos e para as nações. Mas é preciso estar atento, pois esse não é um movimento isento de interesses, e pode nem sempre ser construtivo. Numa sociedade onde o conhecimento significa condição de emancipação, é preciso analisar a internacionalização na sua potencialidade de um capital cultural emancipador. Caso contrário, de forma muitas vezes velada, correse o risco de uma geopolítica mundial que reforce as desigualdades e a dependência.

\section{REFERÊNCIAS}

ALTACH, Philip G.; KNIGHT, Jane. The internationalizacion of higher education: motivations and realities. Journal of studies in internacional education, v. 11, n. 3-4, p. 290-305, 2007.

BARTELL, Marvin. Internacionalização of universities: a university-culture-based framework. Higher Education. Manitoba: Winnipeg, 2003. p. 37-52.

BOURDIEU. Pierre. Razões práticas: sobre a teoria da ação. Trad. de Mariza Corrêa. Campinas: Papirus, 1996.

BRAGANÇA, Ângela. Com a palavra, Secretária de Estado Ângela Bragança. Angola Yetu, Publicação do Consulado Geral de Angola em São Paulo. 40 - 1975-1015 - Independência Nacional, São Paulo, ano 3, n. 09, p. 12-15, dez. 2015.

CASTRO, Alda Araújo; NETO, Antonio Cabral. O ensino superior: a mobilidade estudantil como estratégia de internacionalização na América Latina. Revista Lusófona de Educação, v. 21, p. 69-96, 2012. 
CONSTANTINO, Graciane Mondardo. Educação e identidade cultural: experiência de acadêmicos angolanos, BRASIL. 2012. Dissertação (Mestrado em Educação) - Criciúma: Ed. do Autor, 2012.

DIAS Sobrinho, José. Educação Superior, globalização e democratização. Revista Brasileira de Educação, Rio de Janeiro, ANPED, v. 28, p. 164-173, 2005.

DIAS Sobrinho, José. Universidade e novos modos de produção, circulação e produção do conhecimento. Avaliação, Campinas, Sorocaba, v. 19, n. 3, p. 643-662, nov. 2014.

KNICHT, Jane. Internacionalização remodeled: definition, approaches, and rationales. Journal of Studies in Internacional Education. Sage Publications, v. 8, n. 1, p. 5-32, spring 2004.

MERCADO, Roxana. Histórias de legados familiares, mandatos encubiertos y elecciones negociadas. Cuadernos de Edución, Córdoba, ano III, n. 3, p. 175-181, dec. 2004.

MOROSINI, Marília Costa. Estado do conhecimento sobre internacionalização da educação superior - conceitos e práticas. Editora da UFPR. Educar, Curitiba, n. 28. p. 107-127, 2006.

MWEWA, Muleka. Sobre a integração social entre desiguais. In: MWEWA, Muleka; FERNANDES, Gleiciani; GOMES,
Patrícia (Org.). Sociedades desiguais: gênero, cidadania e identidades. São Leopoldo: Nova Harmonia, 2009. p. 7-28.

PEÑA, Daniel. Internacionalização. Que metas? A que ritmo? Que estratégias? Universidade Carlos III de Madri, Espanha. III Encontro Universia de Reitores. Debate 10. Rio de Janeiro, 2014. p. 01-09.

SILVA, Tomaz Tadeu da. A produção social da identidade e da diferença. In: SILVA, Tomaz Tadeu da (Org.). Identidade e diferença: a perspectiva dos Estudos Culturais. 4. ed. Petrópolis: Vozes, 2005. p. 73-101.

SOUSA SANTOS, Boaventura. Dilemas do nosso tempo: Globalização, multiculturalismo e conhecimento. Educação \& Realidade, Porto Alegre, Universidade Federal do Rio Grande do Sul, Faculdade de Educação, v. 26, n. 1, p. 13-32, 2001.

SOUSA SANTOS, Boaventura. Por uma concepção multicultural de direitos humanos. In: SOUSA SANTOS, Boaventura de (Org.). Reconhecer para libertar: os caminhos do cosmopolitismo cultural. Rio de Janeiro: Civilização Brasileira, 2003. p. 429-461.

Recebido em 07-06-2016.

Aprovado em 13-07-2017. 